\title{
Groundwater Dynamics in Pabna District, Bangladesh
}

\author{
${ }^{1}$ M Saiful Islam, ${ }^{2}$ Alam M K, ${ }^{3}$ Rahman M A \\ ${ }^{1}$ Assistant Professor, Department of Physics, Govt. Edward College, Pabna, Bangladesh \\ ${ }^{2}$ Assistant Professor, Department of Physics, Pabna University of Science \& Technology, Bangladesh \\ ${ }^{3}$ Lecturer, Department of Applied Physics \& Electronic Engineering, University of Rajshahi, Bangladesh
}

\begin{abstract}
Groundwater is an important segment of the hydrologic cycle and constitutes about one third of world's fresh water reserves. It has distinct advantages over surface water resources. It is the most dependable resource and is available almost everywhere on land phases. It is hard to overstate the importance of groundwater in the life and economy of Bangladesh. Groundwater supplies over $90 \%$ of drinking water requirements and the vast majority of irrigation water. It is the only source of water supply for drinking and main source of irrigation in the area studied. The increased demands due to over population and development activities have stimulated investigations oriented towards quantifications of this resource. The large scale abstraction of groundwater for irrigation, without proper planning and management, has caused much environmental degradation. So, a detailed study is now essential for the conservation of this important resource in the specific area.

Proper utilization of groundwater greatly precedes the analysis of static water levels in various extents of this inexhaustible resource. The increasing demand placed on it has stimulated to identify of this resource, which would be the basic of its exploration, management and conservation. In this work, quantitative analysis of groundwater resources of Pabna district under Bangladesh has been made. To evaluate the groundwater condition in the study area, some maps and their relative surface patterns have been presented in various ways. Information about the depth of groundwater table is necessary to define groundwater flow directions and determination of suitable well-site locations. It is possible to identify the high permeable zone from the groundwater contour map of an area. Groundwater table contour maps provide useful information to locate new water-wells as the best possible sources of groundwater supply. Groundwater head positions determine the potentiality of any place of the investigated area. The water head position map represents groundwater flow direction.
\end{abstract}

Keywords: Contour map, Groundwater, irrigation.

\section{Introduction}

Groundwater is an important natural source of water supply throughout the world. It is a precious and most distributed resource. The use of groundwater is increasing day by day in irrigation, domestic water supply, municipalities, and rural areas and in industries. The source of groundwater is either precipitation or seepage from large water bodies like reservoirs, lakes, sea or ocean.

Recent studies in groundwater development for irrigation have proven the suitability of the alluvial aquifers in Bangladesh among the most productive in the world. The aquifer is annually recharged through rainfall and flooding and replenishment every year except underneath Dhaka city where an imbalance between recharge and abstraction has been established. But in many localities, rates of withdrawal have exceeded those of natural replenishment and various difficulties have risen in the study area. To achieve intensive irrigation for year round cropping and constant supply of groundwater in various purposes, investment should be applied for sustainable water supply and ecological balance in this area.

\section{General Features of The Study Area}

The study area, Pabna district, is located in the south-eastern corner of greater Rajshahi division (Fig.1).The area comprises nine upazillas covering 2371.50 Sq.Km. The two major rivers, the Padma and the Jamuna flowing along the boundaries of the study area are sustaining the environmental balance and socioeconomic development. The entire study area is almost a plain land of an average elevation of $14 \mathrm{~m}$ whereas the northwestern part is slightly more elevated with maximum elevation of $22 \mathrm{~m}$. The investigated area is located in the shelf region zone of Bangladesh and was formed by the deposition of sediments carried by the river Padma and its tributaries in the Pleistocene age. The alluvium is composed of clay and sand of different grains. The overall soil quality is very much suitable for groundwater potential. The topmost formation, composed of clay and silt, is underlain by fine, medium and coarse sand. The aquifer system in the investigated area may be schematized into an aquifer of variable thickness. 


\section{Materials and Methods}

The successful implication of any research work largely depends not only on the availability and quality of data but also the methodology. Since the groundwater is a hidden resource, as a result it is far beyond the access of direct visual measurement and experiment. However, present research has conducted through data acquisition. Because analysis have been made on integrated hydro-geological approach.

Borehole information would provide valuable information of subsurface water bearing formations and helps to estimate the different hydro-geological parameters. Finally, the computer simulation of the estimated hydro-geological parameters and lithological information would provide a model of the groundwater regime. 303 borehole data were collected from various organizations, namely the "Panasi Project" under BADC, the Soil Research Institute and Bangladesh Water Development Board (BWDB).

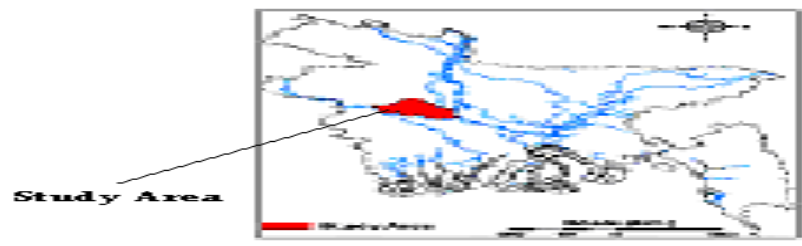

Pabua District

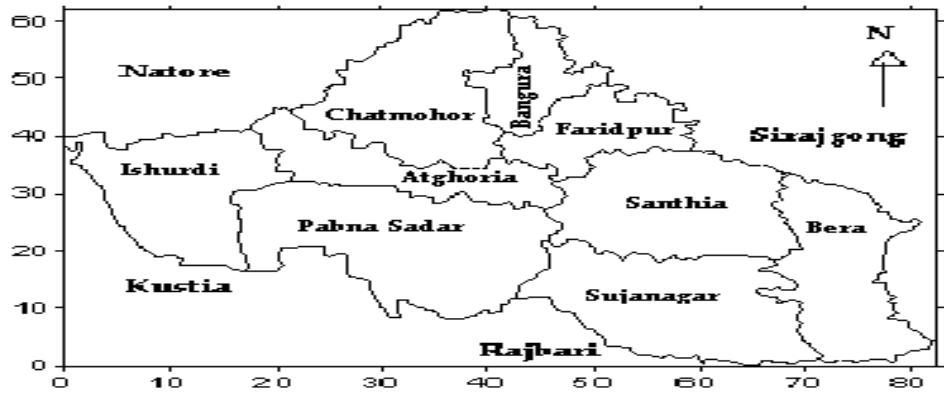

Fig.1: Representation of the study area map.

\section{Analysis of Static Water Level Data}

All porous and fissured rocks below a certain level of earth surface are saturated with water. The upper surface of this groundwater is called the water table. The depth of the water level also known as the static water level below ground surface as observed from the field measurement during borehole is called the water table. Water level data is very much essential to demarcate the position of water, its flow direction and the potentiality of groundwater of any region under investigation. To construct the groundwater flow model observation well data is an important input parameter. To identify the groundwater condition of the investigated area, the groundwater observation well data of 83 locations for the year of 19962007, have been collected and presented in the form of distribution over the area as shown in Fig.2. The distribution of wells is not uniform all over the study area. Bera, Faridpur and Bhangura upazillas have the lowest number of wells and the rest of all the upazillas have the considerable number of wells. A higher depth of water table usually observed during pre-monsoon season (April-June) and lower during post-monsoon (September-November). April and September indicate the higher and lower depths of water table of the study area respectively.

\section{Water Table Map}

The upper surface of the zone of saturation is called the water table which separates the zone of saturation from the overlying zone of aeration. But definitely it is graphic representation of the hydraulic slope of the free water body and is usually a "subdued replica" of the surface topography. The water table is higher in regions of heavy rainfall or in places situated near lakes and rivers. On the other hand, it is low in mountainous regions and on steep slopes. The water table fluctuates from time to time. It is higher in the rainy season and lower in dry season (Mahajan,1989). 


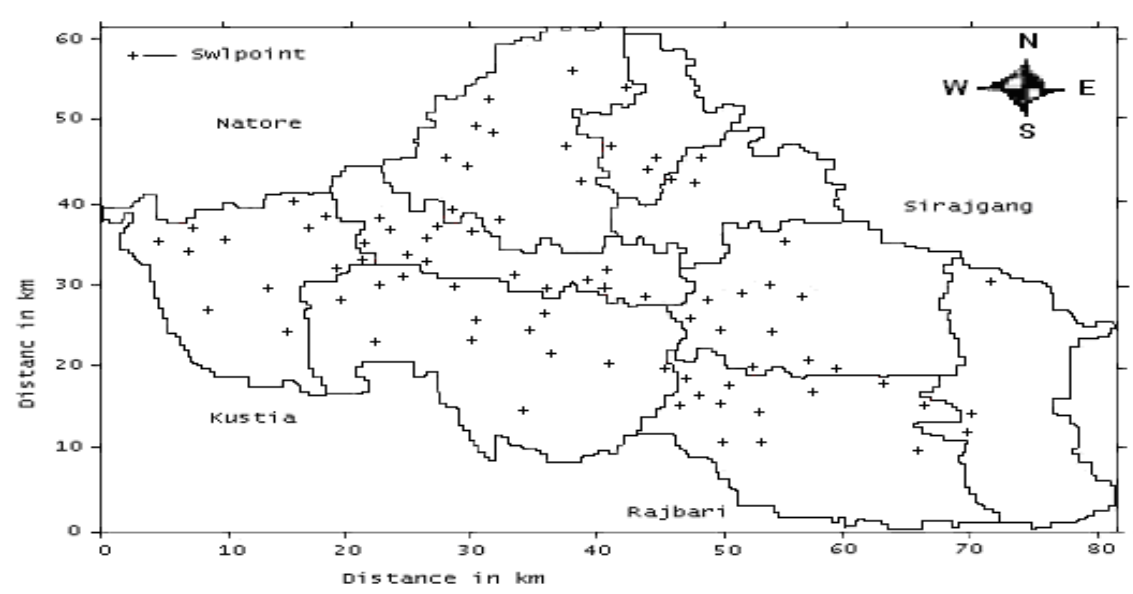

Fig.2: Groundwater observatory well locations of the investigated area

\section{Water Table in Dry Season}

The water table map is a map of phreatic surface, it can be prepared for specific period. The maps are prepared by the water levels of all the observation points on a topographical map and connecting points of equal water table elevation. For studying groundwater dynamics, well hydrographs have been prepared with the information of 83 observatories covering each upazilla of the area investigated. Fig.3(a) shows the water table contour maps for dry season of the years 1993, 2001 and 2008. In this season, the maximum and minimum depths to the water table are recorded as $10.50 \mathrm{~m}$ and $3 \mathrm{~m}$ respectively. It is obvious that the water table is not horizontal and several highs and lows are clearly marked. It is observed from Fig.3(a) that in the dry season of the year 1993, the depth of the water table of the study area varies from $3.50 \mathrm{~m}$ to $9.50 \mathrm{~m}$. The other two maps of dry season of the year of 2001 and 2008 clearly show a declination of groundwater level in the study area. In the central part of the area $2 \mathrm{~m}$ fall of water table in dry season is recorded during the period of study.

\section{Water Table in Wet Season}

The water table contour maps of the area in post monsoon have also been prepared and shown in Fig.3(b). After monsoon the maximum depth to the water table is recorded as $4.20 \mathrm{~m}$. From the water table contour maps it is observed that the variation of water table after rainy season in the year of 1993 is observed between $1-4 \mathrm{~m}$. The same variation is also found in the year of 2001. But in 2008, the water level comes nearer to the surface. It indicates higher recharge of groundwater that may be due to the increased rainfall on that area.

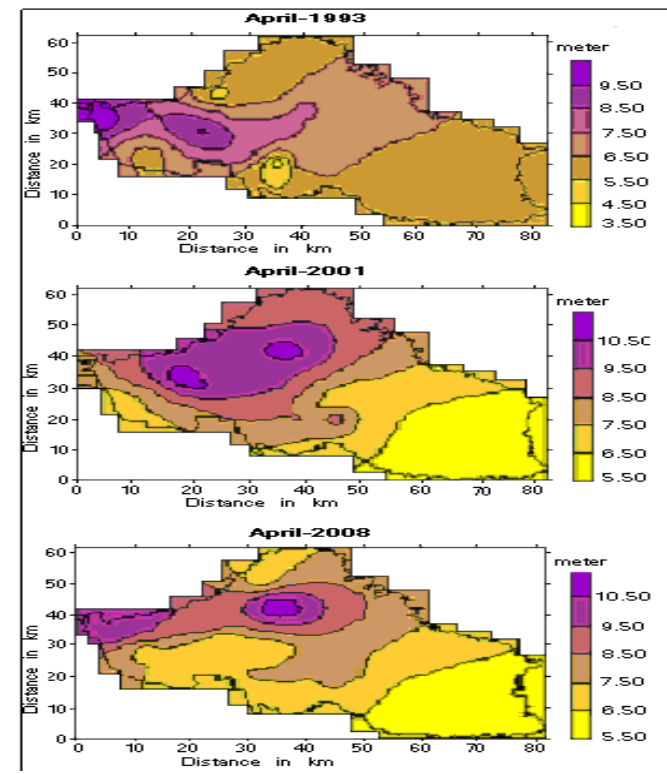

Fig.3(a) Water table in dry season.

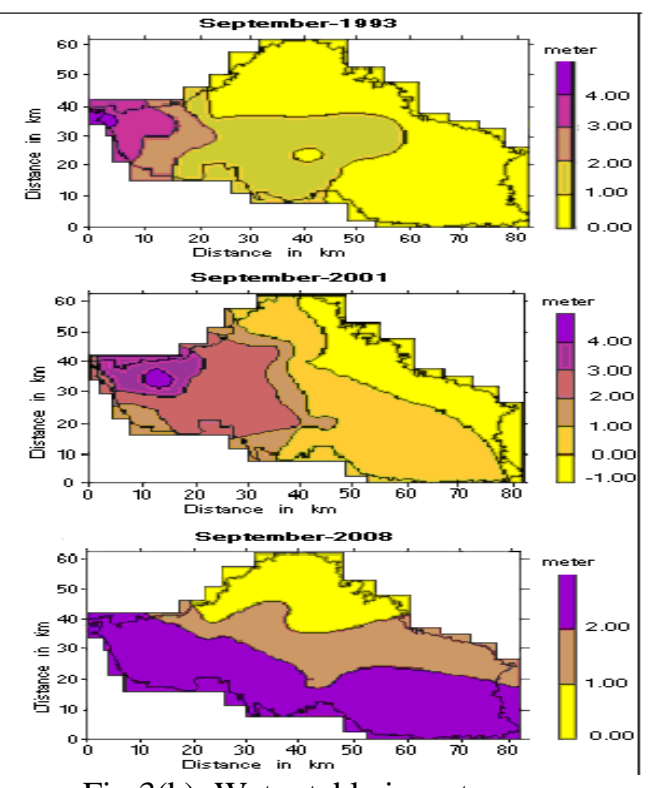

Fig.3(b): Water table in wet season

Fig.3: Contour maps of water table 


\section{Trend of Variation of Water Table}

Seasonal variations of water tables of eight upazillas of Pabna district have been presented in Fig.4. It is observed from the figure that the declining tendency is obvious in the observation wells of Chatmohor, Sujanagar and Bera upazllas. The observation wells could not cover up their initial states. In Chatmohor, water level has been declined around $4 \mathrm{~m}$ with the reference year 1993. The water level in Sujanagar has been declined to $2.5 \mathrm{~m}$ with respect to the reference year. But it is remarkable that the water level in that upazilla contains an almost sustainable position with the previous two years. In Bera, the declining nature is found in a continuous form. This indicates the harmful signal for that region. The rest five upazillas have almost satisfactory conditions of water level with respect to the reference year.
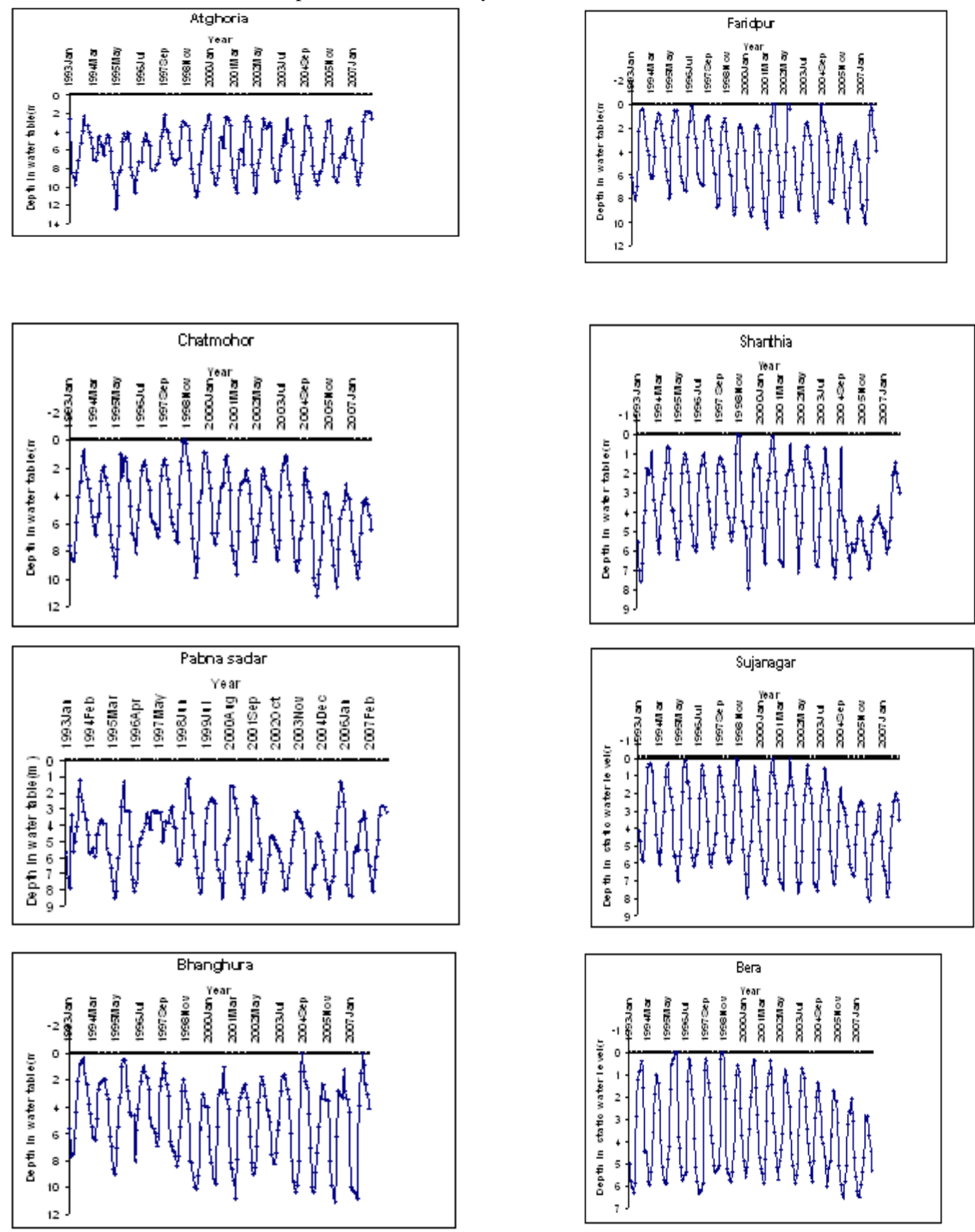

Fig.4: Trend of variation of water table in various upazillas of the study area 
Pre-monsoon: Evaluation, development and management of groundwater resources are often handicapped by non-availability of historic water level data which are required for assessing the changes in storage of groundwater in response to rainfall, evaporation, pumpage, surface irrigation, soil conservation, urbanization and a host of other causes. Historic water level data are also essential for forecasting future trends of water levels in response to the adoption of modern concepts in groundwater reservoir operation (Karnath,1990). A careful continuous monitoring of water table is very important for any planning related to the groundwater development of any particular area.

On the basis of monitoring data of both pre-monsoon and post-monsoon for the years from 1997 to 2007, an attempt has been made to determine the change of the depth of water table in each upazilla with reference to the water table of the year 1996. The records of 1st April of the observation well were taken into consideration. The Fig.5 represents the trend of the change of water table in the study area. The figures relate the real condition of groundwater reserves of the area. It is observed from the figure that in pre-monsoon period the static water level of the study area is declining with reference to the water level of the year 1996. In most of the areas a permanent fall of groundwater level is occurred. In Sujanagar it is the maximum of $2 \mathrm{~m}$. Fig. 6 shows the trend of variation of water level of nine stations which reflects a gradual trend of water table declination in summer in the study area.
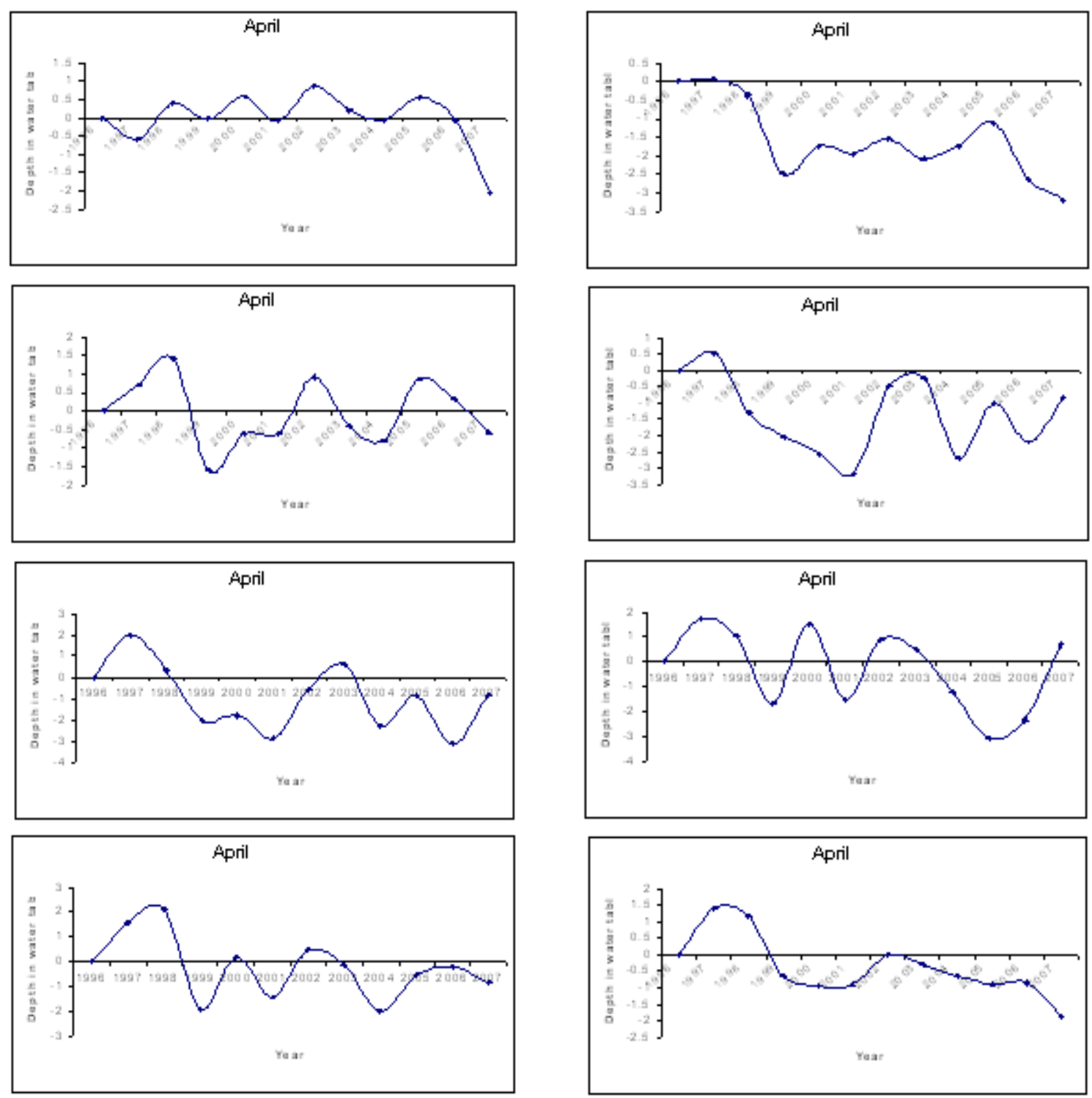

Fig.5: Trend of variation of water table with reference to the year 1996 for nine locations of the study area. 


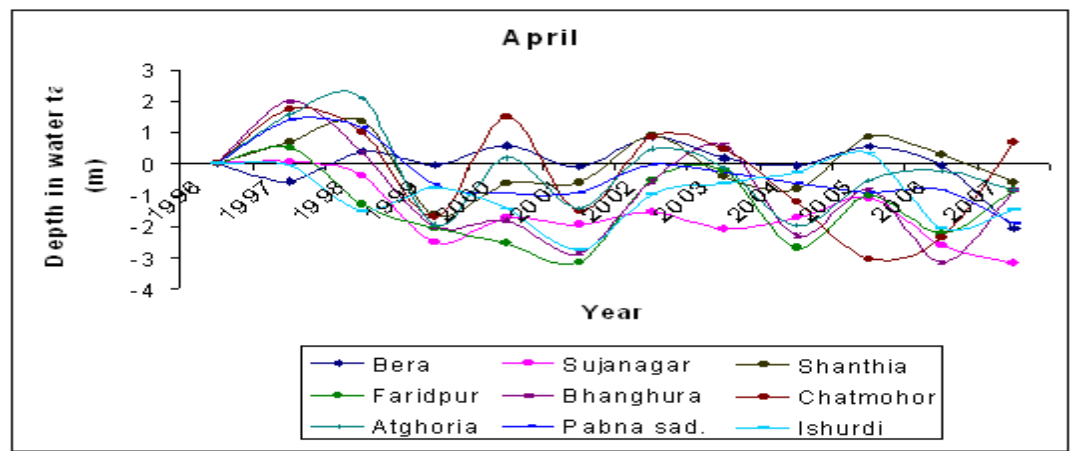

Fig.Error! No text of specified style in document.: Change of the trend of static water level during pre-monsoon of the period 1996-2007 with respect to 1996.

Post-monsoon: The main source of groundwater recharge is the annual precipitation during the monsoon season and the groundwater level goes up after the post monsoon period. The graphical representation of water levels in the month of September of the six upazillas (Fig.7) are representing the amount of variation of recharge happened in individual years with reference to the year 1996. From the figures it could be said that the water level after post monsoon period is also declining in the area. In most of the cases a gradual declinations are clearly observed. The impact of these phenomena is affecting the groundwater reserve. If it continues in long term, environmental degradation will happen there. The change of the trend of static water level during the post-monsoon period of 1996-2007 with respect to the year 1996 has been presented in Fig.7. The water level information of the 16th September of individual years has been taken into account. From the figure it is observed that in post-monsoon season the water levels of Bera, Sujanagar, Shanthia, Bhangura and Faridpur have highly been declined with reference to the year 1996. The maximum declination is observed in the area of Faridpur of $2.5 \mathrm{~m}$. The remaining upazillas have the sustainable conditions of water level with the reference year 1996. If the trend of declining nature continues, the wells of the area will be affected in getting sufficient groundwater in the time of demand. Fig.8 shows the trend of variation of water level of nine stations which reflects a gradual trend of water table declination in wet season in the study area.
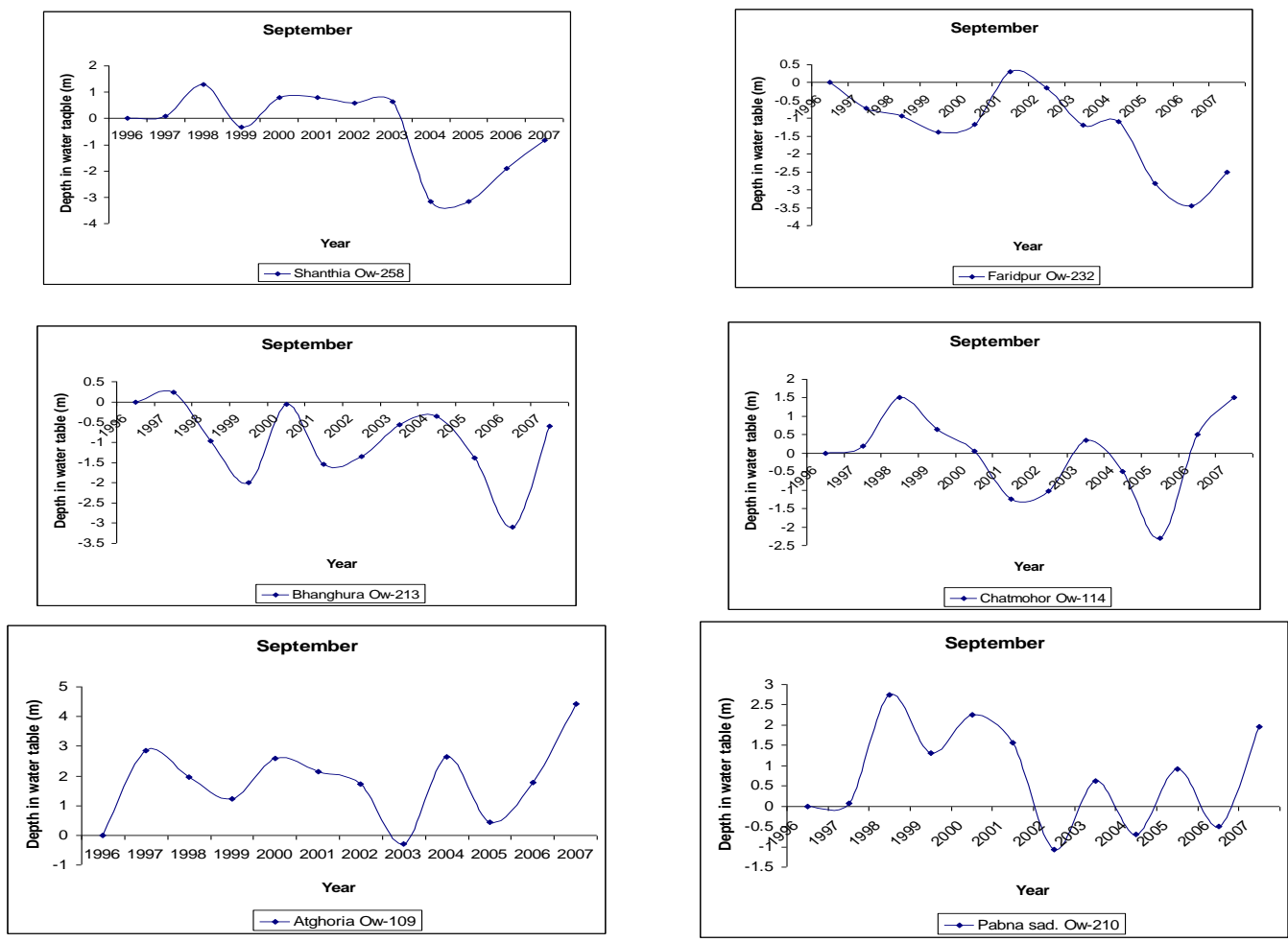

Fig.7: Change of the trend of static water level during post-monsoon of the period 1996-2007 with respect to 1996. 


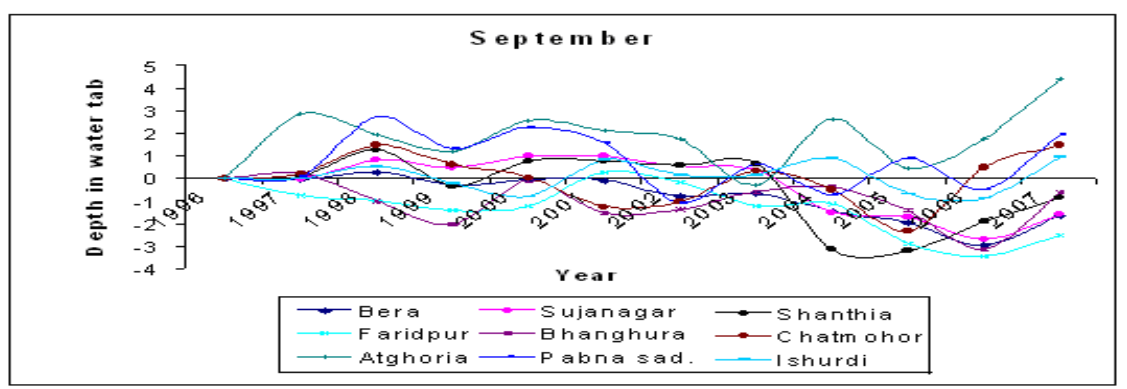

Fig.8: Change of the trend of static water level during post-monsoon of the period 1996-2007 with respect to 1996.

\section{Water Head Map}

The position of the water table with respect to the mean sea level (msl) is generally known as water head position. The water level data is converted into water head position knowing the elevation of corresponding points from the contour map of the surface. Groundwater head gradient plays an important role in exploration of groundwater. An area with high gradient of groundwater head means low conductivity and hence it is not suitable for bulk extraction and low groundwater head gradient is potential for groundwater and suitable for water-wells.

\section{Water Head Position in Dry Season}

The contour maps of water head position of the area in dry and rainy seasons of the year 1993-2008 have been prepared (Fig.9). It is observed from the figures that the water head gradient is very low in the eastern side and is very high in the western part of the study area. In the rest part of the area considerable gradient is also recorded. These figures illustrate that the flow of underground water originates from the western side and some portions of the middle part of the study area. It is also observed that there are few pockets in the northern, middle and southeastern parts of the stud area towards which water may flow from the higher heads. Since the water head positions in the western part have a sloping nature towards the southeastern side, water may flow towards the southern and the eastern parts of the study area.

It is ascertain from above figures that irrespective of season the groundwater flow of the area studied is originated from the northwestern corner. These figures show that the groundwater natural flow direction also originates from the same corner of the investigated area.

\section{Water Head Position in Wet Season}

The contour map of the water head position of the investigated area has been prepared and shown in Fig.9. It is observed from the figure that the water head gradient is very low in the eastern side of the area and in the western part it is very high. In the rest part of the area considerable gradient is also recorded. If it is proposed to abstract water from an aquifer of a particular area, it is essential to determine weather and to what extent that aquifer is being recharged by itself and this can only be properly done if the direction of groundwater flow throughout the aquifer is known. In fact, groundwater movement is a three dimensional phenomena and although the dominants of the horizontal components has rightly given stressed, vertical component also play an important role. Thus water moves not only along the horizontal gradient but also in the downward direction from the water table and in places upward towards the water table. These figures illustrate that the flow of underground water originates from the western side and some portions of the middle part of the area. It is also observed from the figures that there are a few pockets in the northern, middle and the southeastern parts of the study area towards which water may flow from the higher heads. Since the water head positions in the western part have a sloping nature towards the southeastern side, water may flow in this region towards the southern part and the eastern part of the study area. From the figures it is clearly observed that in both seasons there are no remarkable changes in water head positions. So the trend of flow nature of groundwater has no change at all. 

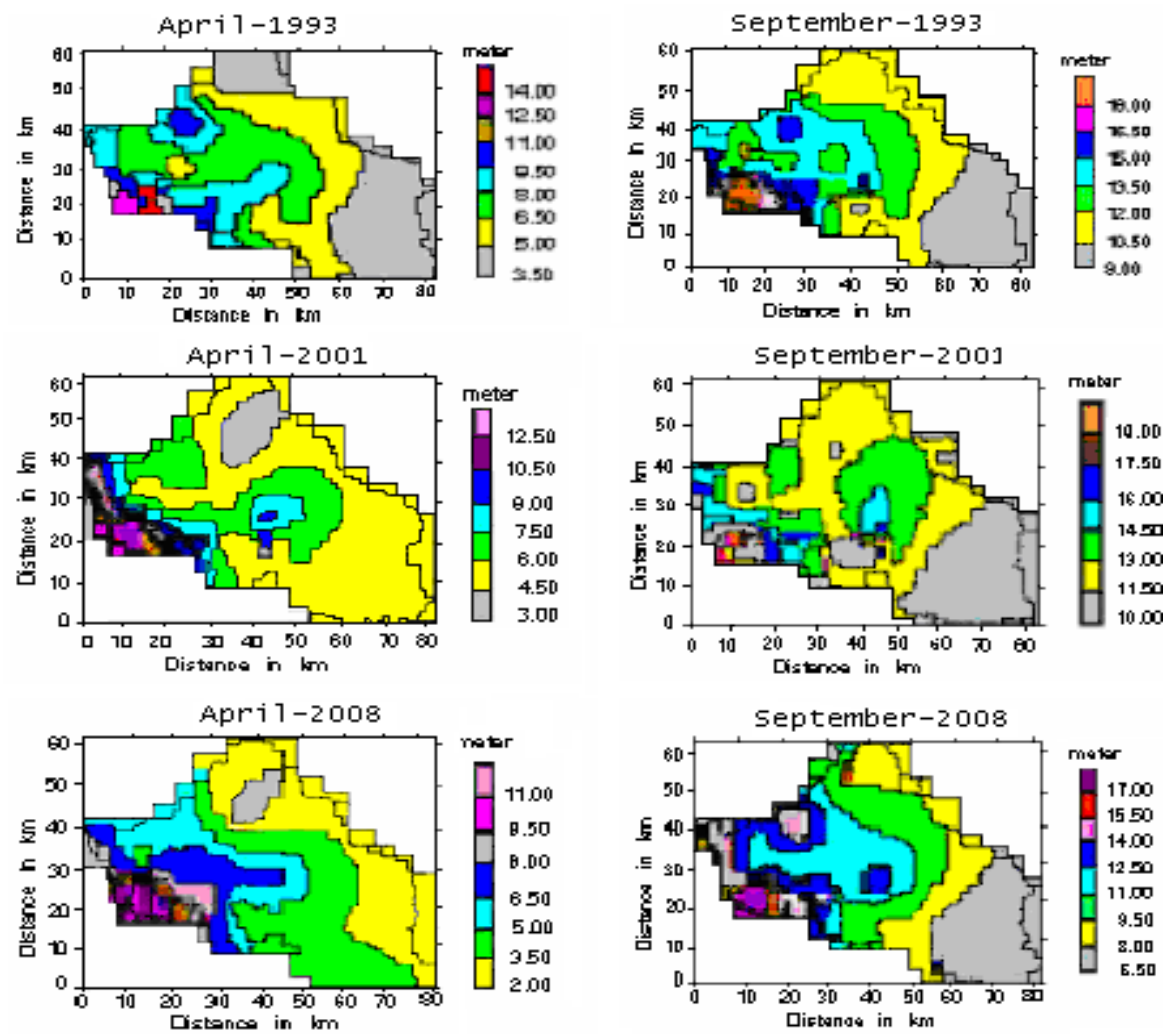

Fig.9: Water head contour maps in pre- and post monsoon period.

\section{Conclusion}

Static water level data provides a great deal of information about groundwater dynamics. Groundwater assessment studies involve correlation of water table fluctuations as recorded in wells with climatic elements dominantly rainfall. Both groundwater storage and rainfall are the part of the hydrologic cycle. The recharge of groundwater is influenced by surface water body and rainfall. On the other hand, groundwater discharge occurs due to abstraction used for various purposes. It is observed that there is a declining nature of groundwater level. This result indicates that recharge and discharge are not in equilibrium condition.

\section{Acknowlegement}

The work has been accomplished in the Geophysics Laboratory of the Department of Applied Physics and Electronic Engineering of Rajshahi University, Rajshahi, Bangladesh, with the full co-operation of the institution of 'Panasi Project' under the department of Bangladesh Agriculture Development Corporation (BADC), Pabna, Bangladesh and the direct supervision of my supervisor who is appointed as a guide for this research work. I am very much grateful to my supervisor and the stated institution for giving me relevant information and advice about the work.

\section{References}

[1] Karnath, K, R., 1990, Ground Water Assessment, Development and Management, McGraw-Hill Publishing Company Limited, New Delhi, India, P. 32-68.

[2] Mahajan, G., 1989, Evaluation and Development of Groundwater, Ashish Publishing House, New Delhi, India. P. 15-78. 